\title{
Uso de estrategias de comunicación en internet de las agencias de viaje españolas
}

\author{
Por Ferran Sabaté, Antonio Cañabate, M.-Andrea Velarde-Iturralde y Raquel Griñón-Barceló
}

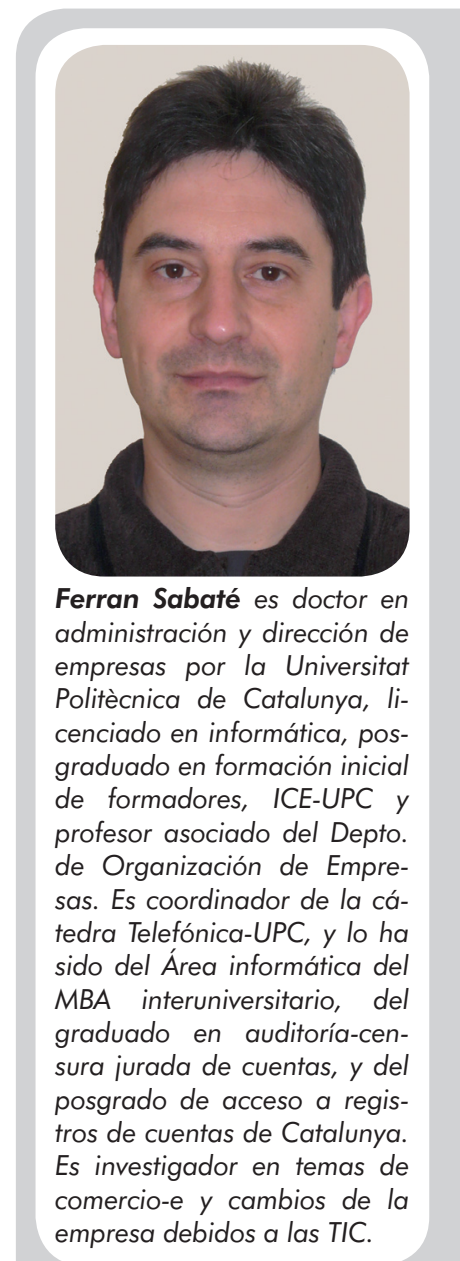

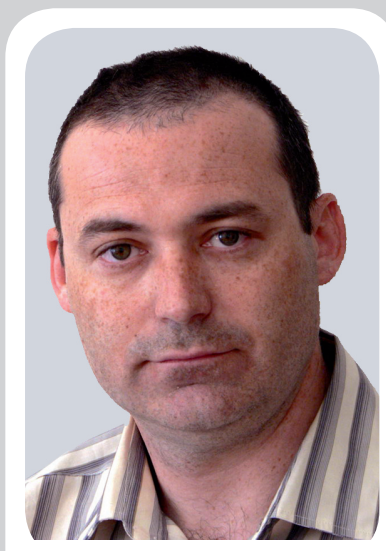

Antonio Cañabate es profesor de la Universitat Politècnica de Catalunya (UPC) en el área de organización de empresas. Ha sido vicedecano de la Facultad de Informática (UPC) donde imparte materias de administración de empresas. Ha asesorado a la Generalitat de Catalunya en la planificación del sistema universitario. $\mathrm{Ha}$ participado en varios proyectos de investigación en los programas europeos Tempus, Comett y Phare-Ace. Sus intereses de investigación se centran en el uso empresarial de las TIC: eMarketing, comercio-e, innovación y productividad, con especial énfasis en los servicios.

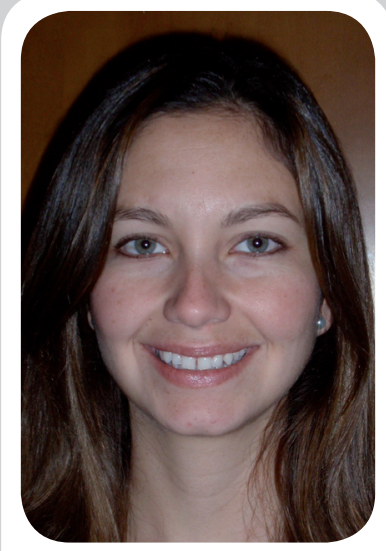

M.-AndreaVelarde-Iturralde cursó los estudios de ingeniería comercial y empresarial en la Escuela Superior Politécnica del Litoral (Espol), Guayaquil (Ecuador), master en negocios internacionales, especialidad en negocios con América Latina, por la Universitat Pompeu Fabra (Barcelona) y posgrado en marketing directo e interactivo por la misma universidad. Compagina su especialización en logística con el doctorado en administración y dirección de empresas por la Universitat Politécnica de Catalunya, centrando su investigación en el marketing y las nuevas tecnologías.

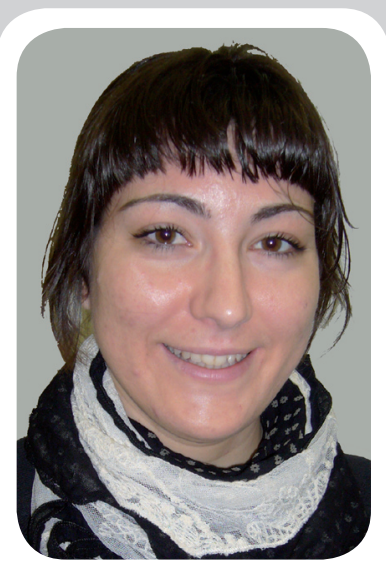

Raquel Griñón-Barceló, doctorando del Departamento de Organización de Empresas de la UPC (DOE), es licenciada en ingeniería en organización industrial y en arquitectura técnica por la Universitat Politècnica de Catalunya, con un posgrado en Construction Manager por el Caatb. Posee una amplia experiencia en el sector de la construcción, en la dirección y creación de grandes proyectos de obra pública y privada. Actualmente compagina la dirección de proyectos con la investigación en los campos de eMarketing, comercio electrónico, innovación y productividad en el mercado.

Resumen: La evolución del marketing tradicional al electrónico se ha dado con la llegada de las nuevas tecnologías de la información y la comunicación, las cuales han repercutido en las estrategias de marketing utilizadas en las empresas. Se intenta cuantificar el nivel de utilización de las estrategias de comunicación basadas en internet. Se analiza el sector de las agencias de viaje al ser uno de los que más invierte en internet. Se discuten los resultados y limitaciones y se proponen líneas de estudio futuras. Las conclusiones pueden ser útiles tanto a directivos como especialistas en marketing.

Palabras clave: Marketing en internet, Publicidad en internet, Estrategias de comunicación, Marketing en buscadores, SEM, SEO, Marketing en medios sociales, Agencias de viaje.

\section{Title: Use of internet promotion strategies by the Spanish travel agencies}

Abstract: The evolution of traditional marketing to e-marketing has been achieved due to the arrival of new information and communication technologies, which have had an impact on the marketing strategies used by companies. The main target of this empirical study is to quantify the level of use of internet promotion strategies. The travel agency sector is selected due to its high level of investment in internet marketing. Results and study limitations are discussed and future lines of research are proposed. Conclusions can be useful to managers and marketing specialists.

Keywords: Internet marketing, Internet advertising, Promotion strategies, Search engine marketing, SEM, SEO, Social media marketing, Travel agencies, M3-Marketing and advertising, M31-Marketing, M37-Advertising.

Sabaté, Ferran; Cañabate, Antonio; Velarde-Iturralde, M.-Andrea; Griñón-Barceló, Raquel. "Uso de estrategias de comunicación en internet de las agencias de viaje españolas”. El profesional de la información, 2010, marzo-abril, v. 19, n. 2, pp. 149-159.

DOI: 10.3145/epi.2010.mar.05 


\section{Introducción}

La comunicación es uno de los ingredientes por excelencia y una de las $4 \mathrm{P}$ del modelo simplificado del marketing-mix, según el cual el plan de marketing se plantea como una combinación de estrategias centradas en producto, precio, comunicación -también llamada por algunos autores promoción- y distribución (McCarthy, 1964). Se han propuesto algunas revisiones a este modelo, siendo las más significativas aquellas relacionadas con el marketing en el sector industrial (Webster, 1984) y en el sector servicios (Booms; Bitner, 1981). Ailawadi et al. (2009) ponen su atención en la promoción del negocio, la comunicación hacia los consumidores y la comunicación en nuevos medios (webs, blogs y otros medios sociales, móviles, etc.) en el caso de las empresas minoristas.

El impacto de las tecnologías de la información y de la comunicación (en adelante TIC), y en especial de internet, sobre el marketing-mix aviva el debate sobre la validez del modelo de las $4 \mathrm{P}$. Algunas propuestas plantean completarlo con otras variables propias del nuevo medio (Strauss; El-Ansary; Frost, 2005). En esta línea Kalyanam y McIntyre (2002) formulan un marco que comprende 11 variables, las $4 \mathrm{P}$ tradicionales y además: personalización, privacidad, cliente, sitio, seguridad, comunidad y promoción de ventas. Otras propuestas como la de Constantinides (2004) rompen con la tradición proponiendo $4 \mathrm{~S}$ (alcance-scope-, sitio, sinergia y sistema) basadas en la experiencia web. Dominici (2009) revisa un buen número de propuestas.

\section{"El plan de marketing se plantea como una combinación de estrategias basadas en producto, precio, comunicación y distribución"}

A medida que el uso de internet se difunde entre la población y el tejido empresarial, la innovación en el comercio electrónico se consolida y el marketing en internet no se queda atrás (Netsuus, 2009; IAB; PWC, 2008). Este ciclo de innovación, tanto tecnológica como de aplicación, conduce a un nuevo paradigma comúnmente referido como web 2.0, caracterizado por permitir al usuario generar, reutilizar e intercambiar contenidos en línea y colaborar fácilmente aprovechando las redes sociales. La web 2.0 enlaza con el concepto de interacción incorporado en la definición de e-marketing de Kalyanam y McIntyre (2002) "intercambio relacional de una forma digital, por medio de redes, en un ambiente interactivo". Dominici (2009) plantea la interacción a través de la variable comunicación del marketing-mix tradicional y también de los elementos multimedia y de interrelación. En internet, el planteamiento de marketing uno-a-muchos pierde fuerza en favor del planteamiento muchos-a-muchos, gracias a su flexibilidad para enviar mensajes personalizados a los clientes y que estos adopten un papel activo.

Cualquier planteamiento de marketing debe tener en cuenta el comportamiento del consumidor ante aspectos tales como la identificación con la marca, el proceso de decisión de compra, la fidelización y otros que caracterizan su conducta. El interés por este campo precede al fenómeno internet. Barnes et al. (2007) aportan una revisión actual de la literatura que considera la influencia de internet en el comportamiento del consumidor y establece una clasificación de consumidores propia de este canal, testeada mediante una encuesta a usuarios de distintos países, que da lugar a tres categorías: escépticos adversos al riesgo, compradores en internet de mente abierta y buscadores de información reservados.

\section{"El sector de las agencias de viaje es uno de los que más invierte en internet"}

Interesa conocer los factores que influyen en la decisión de compra de los consumidores, consideradas las cinco fases del proceso: reconocimiento de la necesidad, búsqueda de información, evaluación de alternativas, decisión de compra y comportamiento postventa. Consantinides (2004) identifica los elementos vinculados con la "experiencia web" que sirven de herramientas de persuasión al vendedor, identificando como tales: factores de funcionalidad (usabilidad e interactividad), factores psicológicos (confianza, seguridad, eliminación de incertidumbres, garantías...) y factores de contenido (estéticos y de marketing-mix). Kim et al. (2007a) confirman y matizan la lista de factores en el caso específico de las agencias de viaje (en adelante $\mathrm{AV}$ ), hallando como elementos más relevantes la funcionalidad del sitio web, seguido de usabilidad y seguridad y, en última instancia, la existencia de tarifas baratas. Si bien estos autores centran su investigación en los factores asociados al sitio web del comerciante, el proceso de compra se ve también afectado por las experiencias en línea del cliente antes y después de visitar la tienda virtual. Sarner (2007) completa este cuadro incluyendo elementos como los diferentes formatos de publicidad y el análisis de datos de usuarios (fase de reconocimiento de la necesidad), el marketing contex- 
tual, especialmente en buscadores (fase de búsqueda de información) y las opiniones en blogs, foros, etc. (fase de evaluación).

Las características específicas de internet facilitan a empresas y anunciantes monitorizar y analizar con detalle la conducta del consumidor, así como la efectividad de sus estrategias. Por un lado, los vendedores pueden observar las acciones del consumidor en su sitio web mediante los datos que su actividad genera, lo cual facilita la segmentación de clientes y la personalización de los contenidos y servicios. En esta línea, Zhang y Krishnamurthi (2004) proponen un sistema para optimizar la personalización de promociones a clientes en tiendas virtuales basándose en sus datos de compra recientes. Estas técnicas han tenido un gran avance en la actualidad gracias a herramientas sofisticadas como Google analytics y otras muchas. Por otro lado, pueden analizar la actividad de los consumidores fuera de su sitio web accediendo a abundante información personal (gustos, aficiones, amigos...) que estos comparten abiertamente en las comunidades existentes en la Red (Ailawadi et al., 2009; Orense-Fuentes; Rojas-Orduña, 2008; Shankar; Hollinger, 2007). Otras investigaciones evalúan la efectividad de diferentes formatos de publicidad en línea para atraer la atención del usuario utilizando técnicas como el seguimiento de los ojos -eye tracking- (AIMC; alt64, 2005) o mediante encuestas (IAB; the cocktail analysis, 2009).

\section{"Cualquier planteamiento de marketing debe tener en cuenta el comportamiento del consumidor ante la identificación con la marca, el proceso de decisión de compra, fidelización..."}

Tomando como punto de partida este escenario, nuestro propósito en este trabajo consiste en la realización de un análisis empírico para medir el nivel de utilización de las estrategias de comunicación en internet por las agencias de viaje virtuales (en adelante AVV) o que operan exclusivamente en internet. La elección del tema objeto de estudio se justifica en base a las cifras que indican un importante repunte de la inversión en publicidad en internet, con un total de 482,42 millones de euros en 2007 (un 55,39\% más que en 2006), alcanzando el 6,04\% del total de la inversión en publicidad (IAB; PWC, 2008). Este crecimiento continúa en 2008, según cifras de Asimelec (2009), alcanzando 610 millones. La elección del sector de las agencias de viaje responde al hecho de que es el que más invierte en internet (16,4\%) según $I A B$ y $P W C$ (2008) y, dentro del sector, las AVV concentran la tercera parte de la facturación electrónica total $(D B K, 2009)$. La elección de estas últimas se debe a un intento de homogeneizar los resultados y de acotar el alcance de la observación. Si bien algunos trabajos han tratado el significado de algunas herramientas de comunicación en internet para las agencias de viaje (Xiang; Gretzel, 2010; Schmallegger; Carson, 2008; Suárez-Álvarez et al., 2009), aquí se analiza el uso de un amplio conjunto de estas herramientas.

En el segundo apartado se identifican las principales estrategias de comunicación basadas en internet, que son la base para realizar una observación empírica de su nivel de utilización. Los resultados obtenidos se muestran en el tercer apartado, y en el cuarto se describe el método seguido. Se discuten los resultados, las limitaciones y los futuros análisis en el quinto apartado $\mathrm{y}$, finalmente, se presentan las conclusiones.

\section{Estrategias de comunicación en internet}

Dado que las referencias citadas en el apartado anterior muestran estrategias demasiado genéricas o concretas, se toma como primera aproximación la clasificación de Orense-Fuentes y Rojas-Orduña (2008). Estos autores definen cinco tipos de estrategias en internet: de marca (equivalentes a los anuncios, pero en el canal electrónico), de permiso (basadas en correos electrónicos publicitarios enviados con el consentimiento del usuario), de resultados (basadas en los motores de búsqueda), virales (ideadas con la intención de que sea el internauta quien voluntariamente distribuya el mensaje) y, por último, estrategias en medios sociales que tienen en cuenta el rol activo que juega el internauta en las comunidades existentes en internet.

A partir de estos cinco tipos se ha elaborado una clasificación más concreta y adecuada al proceso de observación realizado (tabla 1). Para cada estrategia se detalla su descripción, el elemento en que se materializa y su dominio de acción en internet. La nueva clasificación divide las estrategias basadas en buscadores en tres categorías (codificadas como SEM $x$, search engine marketing) e integra las estrategias basadas en medios sociales y las virales en un grupo con tres categorías (codificadas como SMM x, social media marketing).

Los elementos utilizados en las estrategias de marca o producto pueden ser banners superiores, banners cuadrados entre texto, inferiores, mini banners laterales y los denominados "rascacielos" (de formato vertical, normalmente situados a la derecha de la web). Se trata de la versión digital de los anuncios tradicionales y su uso requiere tener en cuenta criterios de efectividad según indican diversos estudios. AIMC y alt64 (2005) concluyen que los elementos más efectivos son el ban- 


\begin{tabular}{|c|c|c|c|}
\hline $\begin{array}{c}\text { Nombre de la } \\
\text { estrategia de } \\
\text { marketing }\end{array}$ & Elemento internet & Dominio & Descripción \\
\hline $\begin{array}{l}\text { De marca- } \\
\text { producto. } \\
\text { Anuncio }\end{array}$ & Banner o display & En sitio web & $\begin{array}{l}\text { Publicidad (de marca o producto) análoga a la tradicional } \\
\text { pero en internet. }\end{array}$ \\
\hline $\begin{array}{l}\text { De permiso. } \\
\text { Folleto }\end{array}$ & Correo electrónico & $\begin{array}{l}\text { Base de datos } \\
\text { de usuarios que } \\
\text { consienten }\end{array}$ & $\begin{array}{l}\text { Publicidad recibida mediante correo electrónico con el } \\
\text { consentimiento del consumidor. El emisor puede ser la } \\
\text { propia empresa que se promociona o una agencia. }\end{array}$ \\
\hline $\begin{array}{l}\text { SEM } M^{1} . P P C \text { en } \\
\text { buscadores }\end{array}$ & $\begin{array}{l}\text { Enlace patrocinado } \\
\text { de pago por clic }\end{array}$ & $\begin{array}{l}\text { Buscadores } \\
\text { - Google (Google } \\
\text { AdWords) } \\
\text { - Yahoo y Live } \\
\text { (Yahoo! Search } \\
\text { Marketing) }\end{array}$ & $\begin{array}{l}\text { Enlace patrocinado para que aparezca en las páginas de } \\
\text { resultados de los buscadores cuando el usuario busque } \\
\text { por unas palabras claves que la empresa anunciante ha } \\
\text { contratado. Su aparición también depende de unos crite- } \\
\text { rios de efectividad, puesto que el anunciante sólo paga } \\
\text { por clic realizado. }\end{array}$ \\
\hline $\begin{array}{l}\text { SEM.PPC en } \\
\text { redes de } \\
\text { buscadores }\end{array}$ & $\begin{array}{l}\text { Enlace patrocinado } \\
\text { de pago por clic }\end{array}$ & $\begin{array}{l}\text { Redes PPC vinculadas } \\
\text { a buscadores: } \\
\text { - Red Google } \\
\text { (Google AdSense) } \\
\text { - Redes Yahoo y Live } \\
\text { (Yahoo! Publisher } \\
\text { Network) } \\
\end{array}$ & $\begin{array}{l}\text { Enlace patrocinado para que aparezca en sitios web o } \\
\text { blogs cuyo contenido tenga relación con unas palabras } \\
\text { clave que la empresa que se anuncia ha contratado. Su } \\
\text { aparición también depende de unos criterios de efecti- } \\
\text { vidad, puesto que el anunciante sólo paga por clic rea- } \\
\text { lizado. }\end{array}$ \\
\hline $\begin{array}{l}\text { SEM. } \\
\text { Posicionamiento } \\
\text { o SEO }\end{array}$ & $\begin{array}{l}\text { Lista de resultados } \\
\text { en buscadores }\end{array}$ & $\begin{array}{l}\text { Buscadores } \\
\text { (zona de resultados } \\
\text { orgánicos) }\end{array}$ & $\begin{array}{l}\text { Conjunto de estrategias realizadas para alcanzar un me- } \\
\text { jor posicionamiento en la lista de resultados que el usua- } \\
\text { rio obtiene tras efectuar una búsqueda. Este tipo de es- } \\
\text { trategias no tiene un coste explícito. }\end{array}$ \\
\hline SMM.Viral & $\begin{array}{l}\text { Acción de promoción } \\
\text { basada en contenidos } \\
\text { multimedia habituales } \\
\text { en las redes sociales } \\
\text { (fotos, videos, PDF, } \\
\text { presentaciones } \\
\text { y elementos } \\
\text { interactivos) }\end{array}$ & $\begin{array}{l}\text { Lista de distribución } \\
\text { (BD de correos } \\
\text { electrónicos) y/o } \\
\text { medios sociales }\end{array}$ & $\begin{array}{l}\text { Campañas de promoción en Internet basadas en el con- } \\
\text { tagio (que sea el propio usuario quien transmita viral- } \\
\text { mente el mensaje). Se caracterizan por: } 1 \text { ) basarse en el } \\
\text { uso del correo electrónico o de los medios sociales como } \\
\text { medio de expansión, y } 2 \text { ) campañas o iniciativas origi- } \\
\text { nales realizadas en base a contenidos habituales de las } \\
\text { redes sociales (videos, presentaciones...) que pueden in- } \\
\text { cluir procesos de interactividad. }\end{array}$ \\
\hline $\begin{array}{l}\text { SMM } \\
\text { Interacción } \\
\text { en blog propio }\end{array}$ & $\begin{array}{l}\text { "Apuntes" en blogs y } \\
\text { conversaciones }\end{array}$ & $\begin{array}{l}\text { Blog propio de la } \\
\text { empresa }\end{array}$ & $\begin{array}{l}\text { Tener un primer nivel de presencia en los medios sociales } \\
\text { y aumentar la interactividad con los consumidores a tra- } \\
\text { vés de un blog propio, que permita conversaciones que } \\
\text { mejoren el servicio al cliente y les aporte valor añadido. }\end{array}$ \\
\hline $\begin{array}{l}\text { SMM. } \\
\text { Interacción en } \\
\text { medios sociales } \\
\text { externos }\end{array}$ & $\begin{array}{l}\text { "Apuntes" en blogs y } \\
\text { conversaciones }\end{array}$ & $\begin{array}{l}\text { En los distintos } \\
\text { medios sociales: } \\
\text { - Blogs y sitios web } \\
\quad \text { de fácil edición } \\
\quad\left(\text { wiki }^{5}\right) \\
\text { - Redes sociales } \\
\end{array}$ & $\begin{array}{l}\text { Tener presencia en los medios sociales, escuchar lo que } \\
\text { se comenta de la marca y reaccionar ante comentarios } \\
\text { negativos. }\end{array}$ \\
\hline Elaboración propia & en base a la clasificación d & e Orense y Rojas (2008) & $\begin{array}{l}\text { kipedia.org/wiki/Search_engine } \\
\text { i } \\
\text { i/Search_engine_optimization } \\
\text { ocial media marketing }\end{array}$ \\
\hline
\end{tabular}

Tabla 1. Clasificación de las estrategias de comunicación basadas en internet

ner superior y el rascacielos externo, sobre todo si éste sigue al usuario en su navegación. Por otra parte, parece ser que hombres y mujeres utilizan distintos patrones de lectura de los sitios web, algo que también se confirma en las búsquedas asociadas al sector turístico que realizan los estadounidenses (Kim et al., 2007b).

La estrategia de permiso basada en el envío de un folleto o catálogo digital merece especial mención, en tanto que los catálogos han jugado y juegan un papel importante en las estrategias de comunicación de las AV. En consecuencia, se previó (y se observó) un alto grado de utilización de esta estrategia en internet.
Merecen especial atención las estrategias basadas en buscadores, que Posada (2008) define como aquellas acciones dirigidas a mejorar el posicionamiento de un sitio web en los motores de búsqueda con el fin de incrementar su tráfico. Hay dos maneras de aparecer en las listas de resultados de los buscadores. Una es realizando acciones en el diseño del sitio web (y en su contenido) que mejoren el posicionamiento en la lista (clasificadas como SEM posicionamiento o SEO search engine optimization). La otra es pagando para que aparezcan enlaces patrocinados de forma preferente (clasificadas como SEM PPC en buscadores, haciendo 
referencia a que generalmente se paga por cada clic, pay per click).

Otra posibilidad relacionada con los buscadores es pagar para que aparezcan enlaces patrocinados de pago por clic en sitios web que han aceptado formar parte de la red de distribución del buscador (clasificadas como SEM PPC en redes de buscadores).

En todos los casos, el anunciante debe conocer las palabras clave que utilizan los usuarios al buscar información relacionada con su negocio. Aunque se trata de un área de conocimiento muy novedosa, ya hay algunos artículos académicos publicados (Sabaté et al., 2009a; 2009b; Sen et al., 2008).

La clasificación propuesta incluye estrategias que tienen en cuenta a las comunidades de internautas que se han formado alrededor de los nuevos medios sociales (blogs, wikis, redes sociales, etc.), con acuerdo a su creciente importancia (Ailawadi et al., 2009; Orense-Fuentes; Rojas-Orduña, 2008) también en el caso del sector de las AV (Bernoff; Li, 2008). Toda estrategia basada en la utilización de medios sociales para la expansión exponencial del mensaje promocional se ha clasificado como estrategia viral (SMM viral), y suelen utilizar contenidos multimedia. La presencia de una $\mathrm{AV}$ en los medios sociales se ha clasificado como una estrategia de interacción, ya sea mediante blog propio (SMM interacción en blog propio) o mediante la participación en blogs de otros para promocionar, controlar o intervenir acerca de lo que se dice sobre la empresa (SMM interacción en medios sociales externos). Esta clasificación integra el factor interacción, que varios de los trabajos citados en la introducción consideraban clave (Dominici, 2009; Kalyanam; McIntyre, 2002).

\section{Resultados}

Los datos fueron recogidos entre enero y abril de 2009.

Para cada una de las estrategias de comunicación analizadas se define una metodología de búsqueda y unos indicadores para medir su nivel de utilización. Los resultados obtenidos se muestran en la tabla 2, mientras que los detalles metodológicos se explican en el siguiente apartado. Asimismo, se incluyen dos de las principales agencias de viaje tradicionales (en adelante, AVT), para comprobar si pudieran existir diferencias entre ambos tipos de agencia.

\section{“Hay que destacar Atrápalo y eDreams, para las cuales hay evidencia de utilización de casi todas las estrategias tratadas"}

En primer lugar sorprende el bajo número de anuncios de marca o producto que realizan las AV. Respecto a los banners, tan sólo Mucho viaje parece usar esta estrategia, y en el caso de los rascacielos, ninguna AV los utiliza. Por otra parte, todas las agencias sin excepción -incluso las dos tradicionales- enviaban folletos o catálogos por internet.

Todas las AV utilizan enlaces patrocinados en las páginas de los buscadores Google y Yahoo, con resultados similares en ambos, aunque se aprecia una menor utilización en las AVT. También se observa un uso general de enlaces patrocinados en las redes de influencia de los buscadores, si bien en este caso eDreams, Rumbo y Atrápalo destacan sobre el resto. Casi todas las AV incluyen enlaces patrocinados en las redes sociales. Con respecto a las estrategias SEO se observa cierto nivel de utilización, ya que todas las AV logran posicionarse en la primera página de resultados de los buscadores.

Se observa mayor disparidad de resultados en el conjunto de estrategias de social marketing. Cuatro de las AV (todas virtuales) tienen blog propio, y en dos de ellas se han localizado vídeos que podrían identificarse con campañas virales. Se constatan mayores indicios de utilización de estrategias de interacción en Atrápalo, Mucho viaje y eDreams. De las dos tradicionales, se deduce un nivel bajo de utilización de estas estrategias, si bien Marsans tiene presencia en Facebook.

En cuanto a agencias, hay que destacar Atrápalo y eDreams, para las cuales hay evidencia de utilización de casi todas las estrategias tratadas. El resto usa unas estrategias más que otras. Y las tradicionales parecen tener una menor utilización de estas estrategias en internet, si bien tienen cierto grado de presencia.

\section{Metodología de observación utilizada}

\section{Aspectos previos}

Un primer paso es la identificación de las palabras clave (keywords) representativas del sector y del producto o servicio que ofrecen las AV. Se trata de un aspecto clave en tanto que algunas estrategias se basan en ellas, o bien facilitan la organización de las búsquedas realizadas. El proceso seguido para su elección es el siguiente: 1) como punto de partida se tuvieron en cuenta las 10 palabras clave del sector Turismo-AV que la aplicación en línea de Netsuus proporciona según datos de los últimos tres meses (último trimestre 2008 en este trabajo); 2) se tuvieron en cuenta otras 50 con más tráfico del sector de turismo online, extraídas de Netsuus (2007). Con estos resultados fue posible seleccionar las palabras clave en base a criterios de repetición y posición de ambos listados, manteniendo un equilibrio entre las genéricas y las de marca. 


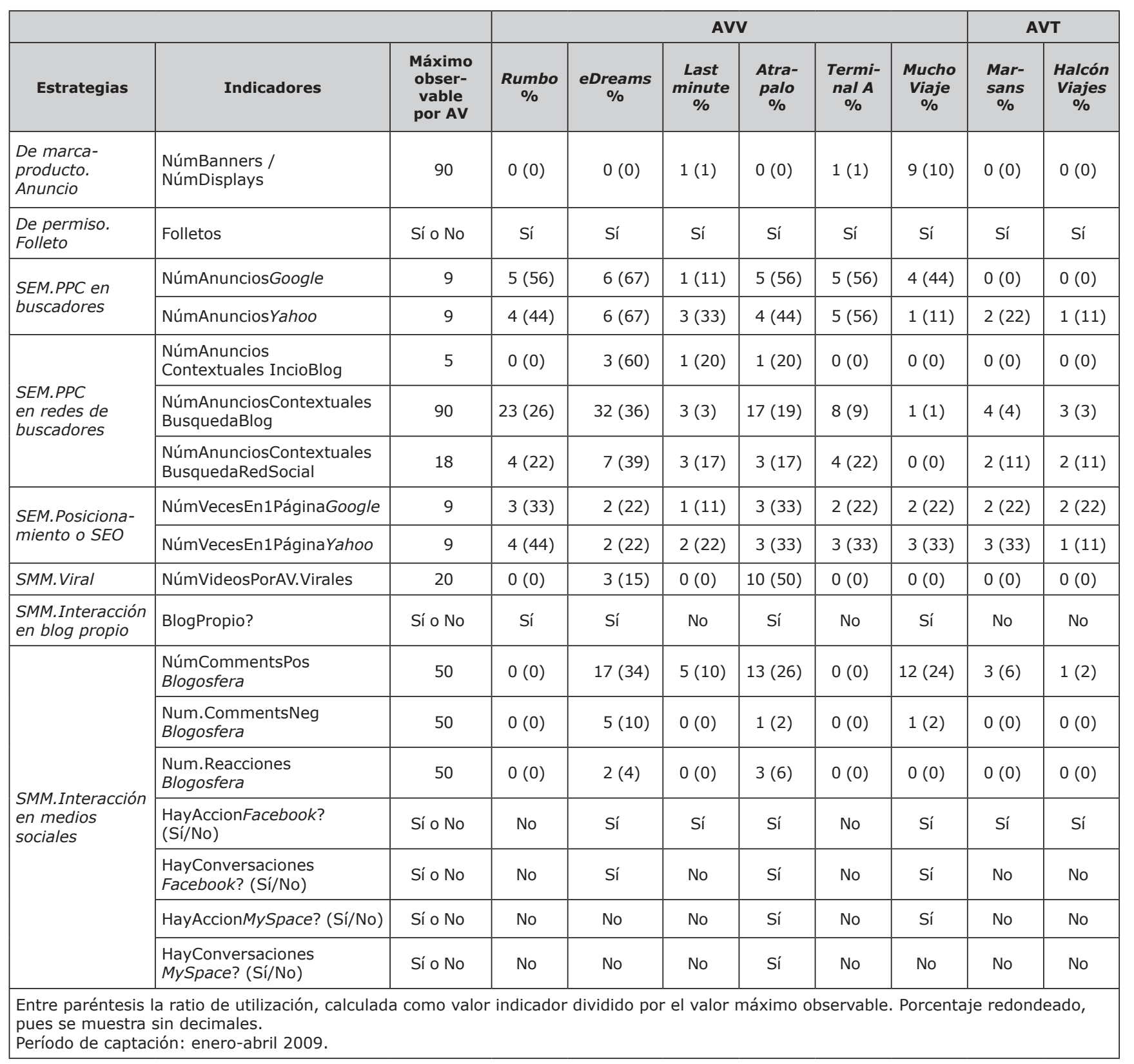

Tabla 2. Resultados globales

Las nueve seleccionadas fueron: vuelos baratos, viajes, vuelos, viajar, vuelos bajo coste, Atrápalo, eDreams, Rumbo y Lastminute.

El segundo proceso consistió en identificar las AVV en las que se centraba la observación. Esto se realizó priorizando aquellas con mayor tráfico en su sitio web y con mayor nivel de facturación en España (según datos de Hoteltur). La metodología seguida fue:

- la lista inicial se corresponde con las AV cuyo nombre está en la lista de palabras clave seleccionadas;

- se amplía la lista buscando en Google enlaces relacionados con cada una de las AV ya identificadas (comando Google related), añadiendo las AV nuevas listadas en la primera página de resultados;

- se eliminan las AV no virtuales, al ser este el objeto de estudio;
- de las 7 identificadas se elimina Viajar.com al tener un nivel de tráfico muy inferior al resto.

Inicialmente las AVV seleccionadas fueron (ordenadas por tráfico): Lastminute, Atrápalo, Mucho Viaje, eDreams, Rumbo y Terminal A. Posteriormente fueron añadidas dos de las AVT con mayor facturación, con la intención de intuir si pudiera haber diferencias entre ambos tipos.

Finalmente se realizó un tercer proceso, que consistió en identificar los 5 blogs de mayor tráfico relacionados con el sector Turismo-AV. Esta lista de blogs se requiere como dominio de búsqueda en algunas de las estrategias analizadas. El procedimiento de identificación fue el siguiente: 1) seleccionar una lista inicial de blogs mediante la aplicación Google Blog Search. La búsqueda incluía todas las palabras clave separadas por la conjunción "OR" y estaba limitada a encontrar 
posts en blogs escritos entre septiembre del 2008 y febrero de 2009. Cinco blogs fueron identificados como válidos por su tema y por el hecho de tener la opción de búsqueda por palabra clave; 2) se amplió la lista a once blogs válidos buscando páginas relacionadas con los identificados inicialmente (comando Google Related); 3) se utilizó el buscador de blogs Technorati de manera complementaria, sin encontrar más blogs; y 4) se ordenaron según su nivel de tráfico (según Alexa), seleccionando finalmente (ordenados por nivel de tráfico): Kirai, Diario del viajero, Locura viajes, Las escapadas, y Por Europa.

http://www.kirainet.com

http://www.diariodelviajero.com

http://locuraviajes.com/blog

http://www.lasescapadas.com/

http://www.poreuropa.com

Tras haber realizado los procesos descritos anteriormente, se procede a explicar la metodología seguida para observar el nivel de utilización de cada una de las estrategias de comunicación en internet listadas en la tabla 1. Para cada estrategia se describirán los indicadores de medición y la metodología seguida para su cuantificación, detallando los parámetros y criterios que se han tenido en cuenta.

\section{Estrategias de marca o producto (anuncios)}

Se trata de acciones publicitarias realizadas en internet para potenciar la marca o el producto. En tanto que los banners superiores son uno de los elementos más efectivos para anunciarse en internet (AIMC; alt64, 2005), se utiliza como indicador el número de banners contabilizados para cada AV (incluyendo los displays). Inicialmente no se consideró el indicador número de rascacielos, pero al ser éste otro elemento publicitario muy efectivo, también se procedió a su medición.

\section{"Las estrategias de marca o producto son muy poco utilizadas por las agencias de viaje"}

El dominio de búsqueda de estas estrategias se reduce a los 10 sitios web españoles con mayor tráfico (según Alexa). Se eliminaron los directamente relacionados con otras estrategias, como son los buscadores o redes sociales y los que no disponían de una opción de búsqueda por palabra clave. Finalmente, se eligió buscar en los sitios web de: MSN, Marca digital, EBay España, El mundo, AS, Terra, El país, Segundamano, Telecinco e Infojobs.
La búsqueda se realizó con las palabras clave del sector y se contabilizó la aparición de banners o rascacielos relativos a las AV que son objeto de estudio.

Durante el proceso sorprendió el muy bajo nivel de utilización que las AV hacían de esta estrategia. Sólo se observaron banners de 3 AVV y con una escasa utilización. No se encontró ningún rascacielos de las AV estudiadas. Este último resultado podría estar relacionado con la selección de los 10 sitios web observados, ya que sólo en uno de ellos aparecían rascacielos.

\section{Estrategias de permiso (folletos y catálogos)}

Esta clase de estrategia aprovecha el potencial de internet para enviar al cliente un folleto o catálogo con fines publicitarios, teóricamente con su consentimiento. El indicador elegido para su medición se basa en constatar la existencia o no de un proceso explícito para subscribirse al envío periódico del folleto o catálogo.

En este caso el dominio de búsqueda fue el sitio web de cada una de las AV analizadas, observando si hay un lugar que permita la suscripción.

Todas las AV utilizan esta estrategia, lo cual se corresponde con la intuición inicial, ya que tradicionalmente se han utilizado los catálogos como forma de comunicación.

\section{Estrategias SEM de pago por clic en buscadores}

Se trata de observar si las AV han contratado la inserción en un espacio destacado de las webs de los buscadores de unos enlaces patrocinados asociados a las palabras clave usadas por los usuarios en sus búsquedas. La idea es que al hacer clic (el anunciante paga por clic realizado) el usuario se dirija hacia una página del sitio web de la $\mathrm{AV}$, que se habrá diseñado para un propósito determinado. Su medición se realiza contabilizando durante el proceso de búsqueda el número de enlaces patrocinados observados para cada $\mathrm{AV}$ en base a dos indicadores, uno para Google y otro para Yahoo.

Las páginas de resultados de ambos buscadores conforman el dominio de búsqueda.

La metodología, dada una AV, es buscar cada palabra clave y contabilizar el total de enlaces patrocinados $P P C$ (pay per click) que aparecen en la primera página de resultados en Google y en Yahoo. Conviene aclarar que si tras realizar una búsqueda hay varios enlaces patrocinados de una misma $\mathrm{AV}$, tan sólo se contabilizará uno, de esta manera puede estimarse un valor teórico máximo observado por compañía y calcularse una ratio de utilización.

Se observó un distinto comportamiento según se buscase con palabras clave genéricas o de marca. El $88 \%$ de los enlaces patrocinados contabilizados provienen de palabras clave genéricas. Del $12 \%$ vinculado a 
marcas, en todos los casos menos uno, al buscar por una marca se obtienen enlaces hacia esa marca. Así pues, en caso de que esté permitido, las AV no suelen comprar palabras clave coincidentes con el nombre de sus competidores. Los datos indican que todas las AV suelen contratar enlaces en ambos buscadores, puesto que los resultados son similares, aunque Google representa un $90 \%$ y Yahoo sólo el 1,64\% según Netsuus (2009).

\section{Estrategias $S E M$ de pago por clic en redes de bus- cadores}

Son similares a las anteriores, pero en este caso los enlaces patrocinados se encuentran en las redes de influencia de cada buscador, esto es, cualquier sitio web que haya pactado con algún buscador la inclusión de enlaces patrocinados a cambio de cierta compensación económica. A efectos de este trabajo, se han considerado como dominio de búsqueda los 5 blogs de mayor tráfico relacionados con el sector (que se han citado en el apartado de aspectos previos) y dos redes sociales (Facebook y MySpace) escogidas entre las 10 con mayor audiencia en España, según datos de La gaceta (febrero 2009) relativos al 2008.

Los indicadores que se definen como medición para cada una de las AV son tres y se calculan según el método descrito a continuación. El primero contabiliza el número de enlaces patrocinados en la página inicial de los cinco blogs; se trata pues, de acceder al sitio de cada blog y contar. El segundo suma los enlaces PPC encontrados tras buscar en el blog por cada una de las 9 palabras clave, fijándose en la primera página de resultados y en la página mostrada al hacer clic en el primer elemento listado. Y el tercero calcula el total de enlaces PPC en Facebook y Myspace tras buscar por cada palabra clave. En todos los casos, si para una AV se encontró más de un enlace patrocinado, sólo se contabilizó una instancia.

Fue una sorpresa observar que no se encontraron enlaces patrocinados en Facebook y que los que aparecieron en MySpace eran todos procedentes del sistema de Google.

\section{Estrategias $S E M$ de posicionamiento (o SEO)}

Se corresponden con aquellas acciones que una empresa realiza para mejorar su posicionamiento en la lista de resultados de un buscador. Básicamente, estas acciones se centran en optimizar el código y el contenido del sitio web, en base a unas palabras clave que se consideran representativas del negocio o producto. En este caso no se trata de pagar por estar en una zona preferencial, sino de estar en la primera página de resultados (Outing; Ruel, 2009) que el buscador presenta al tratar las consultas realizadas por los usuarios. Los dos indicadores utilizados (uno para Google, otro para
Yahoo) contabilizan el número de veces que una AV aparece en la primera página de resultados en el proceso de observación seguido.

Una vez fijados una AV y un buscador, se realizó una consulta para cada una de las 9 palabras clave y se contabilizó el número de veces que la AV aparecía en la primera página de resultados, teniendo en cuenta sólo una en caso de repetición en una misma página de resultados.

Hay que destacar que las palabras clave genéricas generaron el $73 \%$ de las apariciones en primera página y la utilización de una palabra clave de marca posicionaba únicamente a la empresa que se correspondía con la palabra clave.

\section{Estrategias $S M M$ virales}

El termino viral se refiere a campañas de comunicación ideadas con el propósito de que el mensaje lo propague de manera exponencial el usuario de internet, sacando partido de las posibilidades que ofrecen el canal y las redes sociales allí establecidas. Generalmente el mensaje se distingue por su originalidad, formato multimedia y por incluir procesos de interactividad. La observación de este tipo de estrategias es compleja, en tanto que debe poder identificarse un mensaje, que a su vez esté asociado a un proceso de aparición y expansión, que algunas veces puede incluir una dinámica de interacción con los usuarios. Para su medición se ha creado un único indicador, que contabiliza el número de campañas de este tipo.

El dominio de búsqueda se restringe a buscar vídeos en la red social Youtube y presentaciones en Slideshare. La identificación del factor viral requiere un proceso de investigación asociado al elemento (vídeo o presentación) que se sospecha puede formar parte de una campaña viral.

El detalle de la metodología seguida es el siguiente. En el caso de los vídeos, se procedió a buscar en Youtube videos asociados a la marca, utilizando esta como palabra clave. Los parámetros fueron: buscar vídeos de España, en español y catalogados como relevantes por el sistema. En el caso de las presentaciones se siguió el mismo esquema, con los parámetros idioma español y texto completo. En ambos casos, una vez identificado un elemento potencialmente viral, se le seguía la pista hasta obtener evidencia de que formaba parte de una campaña de este tipo. Para cada AV se determinó como máximo observable 20 acciones virales, en correspondencia con la metodología de búsqueda aplicada.

Hay que señalar que no apareció ninguna presentación relacionada con el sector con fines promocionales y que sólo se encontraron vídeos promocionales de carácter viral en dos AVV (eDreams y Atrápalo). Llaman la atención estos bajos niveles observados, puesto que 
los anunciantes tienden a valorar muy positivamente las acciones virales. Cabe la posibilidad de que existan más contenidos de este tipo en otros canales.

\section{"La interacción que una AV puede alcanzar mediante su blog es limitada, debido a que los consumidores desconfían de su neutralidad"}

\section{Estrategias $S M M$ de interacción en blog propio}

Las empresas pueden obtener un primer nivel de interacción implementando un blog. La existencia de este blog sería en sí misma un indicador de utilización de esta estrategia y lógicamente, se ha considerado como tal.

El dominio de búsqueda son los sitios web de las $\mathrm{AV}$, donde se prevé que haya un enlace al blog si éste existe. Y para cubrir el caso de que una AV tuviera un blog no accesible desde su sitio web, se ha ampliado el dominio a los buscadores Google y Yahoo, buscando por nombre de la empresa y la palabra blog.

Se observa que la mayoría de AVV (4 de 6) utiliza su blog como medio de comunicación e interacción, a diferencia de lo que ocurre con las AVT (0 de 2).

\section{Estrategias $S M M$ de interacción en medios sociales externos}

El grado de interacción que una AV puede alcanzar mediante su blog es limitado, debido a que los consumidores o usuarios desconfían de su neutralidad. Es obvio que éstos prefieren expresar su opinión y comentarios acerca de sus experiencias con empresas en blogs o redes sociales externos. Escuchar qué se comenta de las empresas, qué se dice en positivo y qué se dice en negativo, además de otros datos sobre consumidores potenciales, es una acción cada vez más estratégica. En este contexto, este tipo de estrategias tiene como finalidad conocer e intervenir (si procede) en estas conversaciones para proteger y reforzar la imagen de marca o, simplemente, para mejorar la interactividad con el cliente y conocerlo mejor.

La medición del uso de estas estrategias presenta cierta complejidad, lo que aconsejó definir siete indicadores. Los dos primeros pretenden cuantificar qué se dice de la AV en los blogs, contabilizando los comentarios positivos por un lado, y los negativos por otro. El tercero, también centrado en los blogs, contabiliza los comentarios que la AV ha escrito como reacción a lo que se comenta de ella en una conversación. El resto de indicadores se refiere a las redes sociales Facebook y Myspace. Dos de ellos verifican si la AV ha iniciado una acción determinada y los otros dos si la AV ha participado en alguna conversación de la Red. Consecuentemente, el dominio de observación son los blogs y las redes sociales citadas, si bien cabe destacar que la búsqueda es abierta, es decir, no se ha restringido a los 5 blogs de mayor tráfico relacionados con sector que se habían empleado en una estrategia anterior.

La metodología para los tres criterios asociados a los blogs se basa en la utilización de una aplicación gratuita llamada Conversation tracker de Blogpulse, que permite buscar conversaciones entre los numerosos blogs existentes. Para cada AV se buscó su nombre o marca en los comentarios creados en los últimos tres meses, siendo procesados los 50 primeros resultados en busca de comentarios acerca de la $\mathrm{AV}$ positivos, negativos o bien creados por la AV. Para el resto de indicadores asociados a las redes sociales se buscaron acciones o comentarios por marca mediante los mecanismos de búsqueda de cada red.

\section{http://www.blogpulse.com/conversation}

La observación detectó dos grupos de AV, las que presentan cierto grado de interacción en blogs y redes sociales (Atrápalo, eDreams, Lastminute y Muchoviaje) y las que no (Rumbo y Terminal A). Si bien los niveles observados en el primer grupo son modestos, probablemente los blogs externos asociados al sector sean un buen medio para las acciones de comunicación. Podemos ver un ejemplo en Ecetia: una conversación sobre una acción de marketing impulsada por eDreams, en una comunidad de bloggers, donde aparecen comentarios positivos, negativos y de empleados de dicha AV.

http://ecetia.com/2009/01/littlebigplanet-y-lapublicidad-in-game

Hay que destacar que Marsans, una AVT, haya creado una acción y participado en conversaciones en Facebook.

\section{Discusión, limitaciones y futuros estudios}

Los resultados obtenidos (tabla 2) suponen una evidencia de que en conjunto las AVV están utilizando todas las estrategias de comunicación planteadas, siendo éste un signo de cierto nivel de desarrollo y madurez, aun teniendo en cuenta el efecto que pueda tener que el análisis se centre específicamente en las AVV. Parece razonable afirmar que los resultados se corresponden con el alto nivel de inversión del sector en internet.

Otra evidencia es el distinto nivel de utilización que se hace de las diferentes estrategias. En primer lugar, se constata que los anuncios mediante banners o rascacielos sólo son usados por una AV en el caso de los 
banners o por ninguna en el caso de los rascacielos. Llama la atención que, siendo este formato junto con los folletos o catálogos los más directamente identificables con equivalentes en el marketing tradicional, en el primer caso su utilización sea tan escasa, mientras que los folletos son utilizados por todas la AV. Esto refuerza la idea de que el medio es singular y de que las empresas deben reinventar sus estrategias, más que adaptarlas. Esta ausencia de banners y rascacielos o bien se trata de una estrategia intencional de las agencias que encuentran el formato poco adaptado a sus objetivos de marketing en línea, o bien la metodología no ha sido capaz de detectar su uso, en caso de que sea significativo.

En segundo lugar, hay suficiente evidencia de que las estrategias más usadas son las basadas en buscadores, puesto que tienden a ser utilizadas por todas las AV y presentan una mayor ratio de utilización. Es más, parece ser que en las páginas de resultados de los buscadores, la ratio de utilización de los enlaces patrocinados PPC (48\% Google, $43 \%$ Yahoo) es muy superior a la de las estrategias de $S E O$ de optimización del posicionamiento (24\% Google, 31\% Yahoo).

Finalmente, las estrategias basadas en los medios sociales, aquellas con componentes más creativos e innovadores, presentan un nivel de utilización más inicial y disperso, en el sentido de que algunas AV las usan y otras no. Destaca la tendencia a una mayor utilización de las acciones de marketing basadas en los medios sociales. Por un lado y en el caso de las AV en España, Suárez-Álvarez et al. (2009) apuntan a la necesidad de una mayor presencia en estos nuevos medios virtuales. En cuanto a EUA, Xiang y Gretzel (2010) confirman la creciente importancia de los medios sociales para el sector turístico.

\section{"Es interesante el diferente uso de las herramientas de comunicación en internet entre las AVV y las AVT"}

Un aspecto interesante son las diferentes pautas de uso de las herramientas de comunicación en internet entre las AVV y las AVT. A falta de un análisis más detallado, se intuye que las AVV utilizan más los enlaces patrocinados $P P C$. Lo mismo se puede afirmar de las estrategias basadas en medios sociales, pero no resulta tan claro en el caso de las estrategias SEO. Parece confirmarse la intuición de que las empresas virtuales usan más intensivamente las acciones de marketing en internet. En este contexto sería recomendable la realización de un nuevo análisis que incluyera un número suficien- te de AV de ambos tipos, para confirmar las hipótesis apuntadas con mayor rigor científico.

La adaptación de la comunicación impresa al formato virtual podría plantearse en profundidad en un nuevo trabajo que aborde este tema para el sector de las $\mathrm{AV}$, ya que prestan un servicio intensivo en el uso de la información, textual y multimedia.

Para finalizar esta discusión hay que decir que la metodología de observación empleada ha sido diseñada para obtener una foto estática del nivel de utilización de las estrategias de comunicación en internet tratadas. Para este propósito los autores consideran que el diseño propuesto es suficientemente robusto, aun teniendo en cuenta las limitaciones impuestas, por ejemplo, al restringir los dominios de búsqueda en algunas de las estrategias analizadas. En cualquier caso, algunos procesos y algunas de las decisiones tomadas son mejorables, si lo que se pretende es diseñar una metodología con mayor rigor científico. Además cabe tener en cuenta la dificultad para analizar algunas estrategias, como las basadas en los medios sociales o virales. Como ejemplos de mejoras se destaca:

- uso de herramientas de análisis de la densidad de palabras clave para identificar cuáles son las más representativas del sector;

- uso de aplicaciones automáticas de análisis semántico para buscar conversaciones de tono positivo o negativo en la web;

- incluir nuevos indicadores o ampliar algunos dominios en la medición de algunas estrategias.

Procede pues, la realización de nuevos análisis para avanzar en este objetivo.

\section{"Las AVV están utilizando todas las estrategias de comunicación planteadas"}

\section{Conclusiones}

La idea general es que el sector de las AV es uno de los que más invierte en internet, lo cual invita a pensar que es uno de los sectores que utiliza la Red con mayor madurez. Los resultados obtenidos en el proceso empírico confirman esta intuición en el caso de las AVV y en relación a la utilización de estrategias de marketing basadas en internet.

Por otra parte, la medición de las acciones de marketing basadas en internet que utilizan las empresas es en muchos casos bastante compleja. Un ejemplo de ello 
es la dificultad para relacionar un vídeo promocional con una campaña de carácter viral. Este trabajo, además de los resultados observados, aporta una primera definición de una metodología de medición, que es un buen punto de partida para crear nuevas y mejores versiones. Algunos indicadores alternativos para la medición pueden encontrarse en otros textos; por ejemplo, Bernoff y Li (2008) proponen algunos para medir la utilización de los medios sociales en las acciones de marketing, ventas y atención al cliente.

Los datos observados permiten intuir la respuesta a ciertas hipótesis de investigación, tales como: 1) ¿Presentan las empresas virtuales un mayor nivel de utilización de las estrategias de marketing basadas en internet que las convencionales? La respuesta parece ser que sí; 2) ¿Qué estrategias prefieren las empresas, las acciones $S E M$ de $P P C$ en buscadores o las acciones de optimización del posicionamiento en buscadores (SEO)? La respuesta parece ser la primera opción. Este trabajo es un buen punto de partida para la realización de nuevos estudios en las líneas planteadas.

\section{Bibliografía}

Ailawadi, Kusum L.; Beauchamp, J. P.; Donthu, Naveen; Gauri, Dinesh K.; Shankar, Venkatesh. "Communication and promotion decisions in retailing: a review and directions for future research". Journal of retailing, 2009 , v. 85 , n. 1 , pp. $42-55$.

AIMC; alt64. Eyetracking media España - Formatos de publicidad. AIMC, 2005.

http://www.alt64.com/eyetrackingmedia/index.php

Asimelec. Informe 2009 de la industria de contenidos digitales. Madrid: Asimelec, 2009.

Barnes, Stuart J.; Bauer, Hans H.; Neumann, Marcus M.; Huber, Frank. "Segmenting cyberspace: a customer typology for the internet". European journal of marketing, 2007, v. 41, n. 1, pp. 71-93.

Bernoff, Josh; Li, Charlene. "Harnessing the power of the Oh-so-social web". MIT Sloan management review, 2008, v. 49, n. 3, pp. 36-43. www.inforesearching.com/downloads/oh-so-social-web.pdf

Booms, Bernard H.; Bitner, Mary Jo. "Marketing strategies and organization structures for service firms". En: Booms, Bernard H.; Bitner, Mary Jo. Marketing of services. Chicago, IL: American Marketing Association, 1981, pp. 47-51.

Constantinides, Efthymios. "Influencing the online consumer's behaviour: the web experience". Journal of internet research, 2004, v. 14, n. 2, pp. 111-126.

http://www.ecs.umass.edu/ eshittu/Toyin/Influencing\%20Online\%20Consu mers\%20Behaviour.pdf

DBK. Informe especial sobre comercio electrónico de viajes. DBK, 2008.

Dominici, Gandolfo. "From marketing mix to e-marketing mix: a literature overview and classification". International journal of business and management, 2009, v. 4, n. 9, pp. 17-24.

http://www.ccsenet.org/journal/index.php/ijbm/article/view/2606

Interactive Advertising Bureau; PriceWaterhouse Coopers. Estudio de inversión en medios interactivos en España 2007. PWC; IAB Spain, 2008.

Interactive Advertising Bureau; The cocktail analysis. Estudio de eficacia de formatos publicitarios display. $2^{a}$ oleada 2009. IAB Spain research, 2009.

Kalyanam, Kirthi; McIntyre, Shelby. "The e-marketing mix: a contribution of the e-tailing wars". Journal of the Academy of Marketing Science, 2002, v. 30, n. 4, pp. 487-499.
Kim, Dong Jin; Kim, Woo Gon; Han, Jin Soo. "A perceptual mapping of online travel agencies and preference attributes". Tourism management, 2007a, v. 28, n. 2, pp. 591-603.

Kim, Dae-Young; Lehto, Xinran Y.; Morrison, Alaistar M. "Gender differences in online travel information search: Implications for marketing communications on the internet". Tourism management, 2007b, v. 28, n. 2, pp. 423-433.

McCarthy, E Jerome. Basic marketing: a managerial approach. Homewood, IL: Richard D. Irwin, 1964.

Netsuus. Informe turismo online invierno 2009. Netsuus, 2009. www.data-red.com/estudios/archivos/20095314369.pdf

Netsuus. Especial búsquedas viajes - Top 50 período 01/03/2007 al 30/06/2007. http://www.netsuus.com/informe-breve/especial-busquedas-viajes

Orense-Fuentes, Miguel; Rojas-Orduña, Octavio-Isaac. SEO - Cómo triunfar en buscadores. ESIC editorial, 2008. ISBN: 9788473565738.

Outing, Steve; Ruel, Laura. Eyetrack III: Cómo lucen los sitios web a través de los ojos de los lectores (Traducción de Guillermo Franco). http://www.poynterextra.org/eyetrack2004/main-spanish.htm

Posada, Laura; Kavlakli, Manolya. Itec810: Information technology project. Sidney: MacQuarie University, Division of Information and Comunication Science, 2008.

Sabaté, Ferran; Arjones, Roberto; Consolación, Carolina; Cañabate, Antonio. "Estrategias SEM de pago por clic en el sector de las floristerías". $3 r d$ Intl conf on industrial engineering and industrial management - XIII Congreso de ingeniería de organización. Barcelona-Terrassa, 2009a.

http://personal.telefonica.terra.es/web/mdem/CVPublications/SEM\%20en $\%$ 20floristerias\%20(CIO2009).pdf

Sabaté, Ferran; Berbejal, Jasmina; Consolación, Carolina. "La utilización de estrategias SEO en el sector de la venta de libros". Intangible capital, 2009b, v. 5, n. 3, pp. 321-346.

Sarner, Adam. E-marketing improves the customer's buying process. Gartner Research, 2007.

http://www.ismartsoftware.com.au/ismart/images/Bulletin\%20Graphics/ Email\%20marketing\%20improves\%20the\%20customer\%20xperience.pdf

Schmallegger, Doris; Carson, Dean. "Blogs in tourism: changing approaches to information exchange". Journal of vacation marketing, 2008, v. 14, n. 2, pp. 99-110.

Sen, Ravi; Hess, James D.; Bandyopadhyay, Subhajyoti; Jaisingh, Jeevan. "Pricing paid placements on search engines". Journal of electronic commerce research, 2008, v. 9, n. 1, pp. 33-50.

Shankar, Venkatesh; Hollinger, Marie. "Online and mobile advertising: current scenario, emerging trends, and future directions". Marketing Science Institute, 2007.

Strauss, Judy; El-Ansary, Adel; Frost, Raymond. E-marketing. New Jersey: Prentice-Hall, 2005.

Suárez-Álvarez, Leticia; Vázquez-Casielles, Rodolfo; Díaz-Martín, Ana-María. "The role of commitment perceived by the consumer in service industries". Management research, 2009, v. 7, n. 2, pp. 141-157.

Webster, Frederic E. Jr. Industrial marketing strategy. New York, NY: John Wiley \& Sons, 1984.

Xiang, Zheng; Gretzel, Ulrike. "Role of social media in online travel information search". Tourism management, 2010, v. 31, n. 2, pp. 179-188.

Zhang, Jie; Krishnamurthi, Lakshman. "Customizing promotions in online stores”. Marketing science, 2004, v. 23, n. 4, pp. 561-578.

Ferran Sabaté, Antonio Cañabate, María-Andrea Velarde-Iturralde, Raquel Griñón-Barceló

Universitat Politècnica de Catalunya

ferran.sabate@upc.edu

antonio.canabate@upc.edu

andrea_velarde09@hotmail.com

raquelgrinon@gmail.com 